\title{
Noninvasive Helicobacter pylori Diagnostic Methods in Indonesia
}

\author{
Muhammad Miftahussurur ${ }^{1,2}$ \\ ${ }^{1}$ Division of Gastroentero-Hepatology, Department of Internal Medicine, Faculty of Medicine Universitas Airlangga, and ${ }^{2}$ Institute of Tropical \\ Disease, Universitas Airlangga, Surabaya, Indonesia
}

Although the prevalence of Helicobacter pylori infection in Indonesia is lower than that in other countries, $H$. pylori is still an essential pathogen associated with severe gastric mucosal damage and dyspeptic symptoms. Invasive diagnostic methods are not ideal due to the lack of endoscopic centers and high costs without full coverage by social insurance. Among the noninvasive methods, the urea breath test is widely available in Indonesia and has been suggested as the primary option to ensure the successful eradication of $H$. pylori. There has been no local validation for the urea breath test utilizing ${ }^{13} \mathrm{C}$ or ${ }^{14} \mathrm{C}$. The stool antigen test is inexpensive and suitable for use in active infections before and after eradication; however, customs and habits are obstacles to delivering fresh stool on time. Only polyclonal antibodies and qualitative stool antigen test kits with low sensitivity are available. Serology is a widely validated method and has good accuracy, but it cannot distinguish between active and inactive infections. According to our observations, serology is the main choice of experts and patients, as it is simple, inexpensive and widely known. The urine test is an alternative for reducing costs and endoscopic workload, with high accuracy but low sensitivity. Further studies are necessary to prove the validity of the urine test to be used throughout Indonesia, especially in areas with a low prevalence of $H$. pylori infection. In conclusion, the validated urea breath test and the stool antigen test are considered noninvasive practical approaches for the detection of $\mathrm{H}$. pylori infection in Indonesia, with serological and urine tests as alternatives. (Gut Liver 2020;14:553-559)

Key Words: Noninvasive; Helicobacter pylori; Urea breath test; Stool antigen test; Serology

\section{INTRODUCTION}

Some invasive diagnostic methods, such as the rapid urease test, histopathology and culture, have been developed to detect Helicobacter pylori, a Gram-negative bacterium that is the primary cause of chronic gastritis, gastric atrophy and gastric cancer. ${ }^{1}$ Invasive tests are accurate and commonly used in daily practice. However, inexpensive, simple, convenient and userfriendly indirect tests, such as the urea breath test (UBT), the stool antigen test (SAT) and serology, have been introduced to diagnose $H$. pylori infection. ${ }^{2}$

Indonesia consists of 18,108 islands inhabited by 267,842,292 people, the fourth largest population in the world. The prevalence of $H$. pylori infection in Indonesia is $22.1 \%,{ }^{3}$ which is relatively low compared with neighboring countries such as Malaysia, Thailand and the Philippines, with prevalence of $24.3 \%$ to $49 \%, 54.1 \%$ to $76.1 \%$ and $60 \%$, respectively. ${ }^{4-6}$ Water source, age, and religion are risk factors for $H$. pylori infection among several ethnic groups in Indonesia. ${ }^{3}$ The $\mathrm{m} 2$ type of vacA middle region, East Asian type cagA with 6-bp deletion and EPIYT motif, dupA negative, and double-positive jhp0562/ $\beta$ - $(1,3)$ galT are the predominant virulence factors that may associated with lower incidence of gastric cancer. ${ }^{7}$ We found that the complete integrating conjugative elements TFSS $4 \mathrm{~b}$ type were less predominant and tended to have higher severity in the gastric mucosa. ${ }^{8}$ In Indonesia, the prevalence of metronidazoleand levofloxacin-resistant strains is high, but the prevalence of amoxicillin- and tetracycline-resistant strains is low. We suggest that in some regions of Indonesia, clarithromycin- or metronidazole-based triple therapy should be carefully considered for eradicating $H$. pylori. ${ }^{9}$ To counter high rates of metronidazole and clarithromycin resistance, furazolidone-, rifabutin- and sitafloxacin-based therapies might become alternative regimens, while sitafloxacin should be considered for eradication of levo-

\footnotetext{
Correspondence to: Muhammad Miftahussurur

Division of Gastroentero-Hepatology, Department of Internal Medicine, Dr. Soetomo Teaching Hospital, Faculty of Medicine Universitas Airlangga, Jalan Mayjend Prof. Dr. Moestopo No. 6-8, Surabaya 60131, Indonesia

Tel: +62-31-502-3865, Fax: +62-31-502-3865, E-mail: muhammad-m@fk.unair.ac.id

Received on July 30, 2019. Revised on October 4, 2019. Accepted on October 6, 2019. Published online November 8, 2019. pISSN 1976-2283 eISSN 2005-1212 https://doi.org/10.5009/gnl19264

(c) This is an Open Access article distributed under the terms of the Creative Commons Attribution Non-Commercial License (http://creativecommons.org/licenses/by-nc/4.0) which permits unrestricted non-commercial use, distribution, and reproduction in any medium, provided the original work is properly cited.
} 
floxacin-resistant strains. ${ }^{10}$

Dyspepsia is the fifth-highest prevalent diseases among inpatients and the sixth-highest among outpatients in Indonesia. ${ }^{11}$ In addition, a high prevalence of gastroesophageal reflux disease was found in an area of Indonesia with a low prevalence of $H$. pylori infection, with high rates of several risk factors, including smoking, a history of proton pump inhibitor (PPI) use and higher economic group. ${ }^{12}$ However, the use of gastrointestinal (GI) endoscopy in Indonesia is still limited. In 2013, there were only 515 accredited GI endoscopists among 252 million people, for a ratio of $1: 489,320{ }^{11,13}$ In comparison, the ratio of endoscopists to the total population is 1:37,037 in the United States and 1:49,000 in England. ${ }^{11}$ The number of hospitals in Indonesia that are able to provide GI endoscopy services is limited to only 313 hospitals in 33 provinces, most of them on Java Island. ${ }^{11}$ Thus, the use of invasive diagnosis in Indonesia has many obstacles due to the limited availability of endoscopy. In this review, we summarize the current status of noninvasive diagnosis of $H$. pylori infection in Indonesia and make some recommendations (Table 1). ${ }^{14-16}$

\section{UREA BREATH TEST}

During infection, $H$. pylori has the ability to produce highly active urease, an enzyme that converts urea to ammonium and labelled $\mathrm{CO}_{2}$ in the stomach. ${ }^{14,15}$ In the UBT, isotope-labelled urea is consumed by the patient, and then $H$. pylori breaks down urease enzyme products in the stomach. ${ }^{16}$ The labelled $\mathrm{CO}_{2}$ diffuses into epithelial cells, is absorbed into the blood and is excreted through the lungs. ${ }^{14}$ The labelled $\mathrm{CO}_{2}$ is detected in the exhaled breath after 10 minutes and serves as an indicator of the presence of $H$. pylori. ${ }^{16,17}$ With a sensitivity and specificity of more than $90 \%$, the UBT is the best noninvasive method, although it is less reliable in patients with a history of gastric resection or use of PPIs. ${ }^{14}$

In the UBT test, urea is labelled by the stable heavy isotope ${ }^{13} \mathrm{C}$ or the radioactive isotope ${ }^{14} \mathrm{C} .{ }^{18}{ }^{13} \mathrm{C}$-UBT is noninvasive and accurate, but it is relatively expensive due to the requirement for mass spectrometric analysis, which is only available in large cities. ${ }^{13} \mathrm{C}$-UBT is safer in pediatric patients and pregnant women because it does not use a radioactive isotope. Among 34 provinces of Indonesia, ${ }^{13} \mathrm{C}$-UBT is available in only 10 centers in four main cities: three centers in Jakarta and two centers in

Table 1. Helicobacter pylori Noninvasive Tests and the Current Situation in Indonesia

\begin{tabular}{|c|c|c|c|c|c|}
\hline $\begin{array}{l}\text { Diagnostic } \\
\text { test }\end{array}$ & Sensitivity $^{14-16}$ & Specificity $^{14-16}$ & Advantage & Disadvantage & Situation in Indonesia \\
\hline UBT & $95 \%$ & $95 \%$ & $\begin{array}{l}\text { High accuracy } \\
\text { Detect current infection }\end{array}$ & $\begin{array}{l}\text { Less reliable in patients with } \\
\text { history of gastric resection or } \\
\text { PPI consumption }\end{array}$ & $\begin{array}{l}{ }^{13} \mathrm{C}-\mathrm{UBT} \text { and }{ }^{14} \mathrm{C}-\mathrm{UBT} \text { remain } \\
\text { restricted to } 4 \text { and } 6 \text { cities, } \\
\text { respectively } \\
\text { Expensive and uncovered by } \\
\text { social insurance } \\
\text { Ongoing validation }\end{array}$ \\
\hline SAT & $94 \%$ & $92 \%$ & $\begin{array}{l}\text { Inexpensive and not age } \\
\text { dependent } \\
\text { Novel monoclonal antibodies } \\
\text { are not influenced by PPI } \\
\text { ICA-based, does not require } \\
\text { special equipment or experts }\end{array}$ & $\begin{array}{l}\text { Inconsistent accuracy based } \\
\text { on antigens } \\
\text { Accuracy influenced by } \\
\text { incubation time and stool } \\
\text { condition }\end{array}$ & $\begin{array}{l}\text { Most centers use ICA-based } \\
\text { tests, but with low sensitivity } \\
\text { Collecting stools is more difficult } \\
\text { than collecting blood samples }\end{array}$ \\
\hline Serology & $90 \%$ & $80 \%$ & $\begin{array}{l}\text { Saves costs and reduces } \\
\text { endoscopic workload }\end{array}$ & $\begin{array}{l}\text { Less accurate in children } \\
\text { Wide range of cutoff values } \\
\text { Cannot distinguish between } \\
\text { current and past infections } \\
\text { Lower accuracy than ICA-based } \\
\text { tests }\end{array}$ & $\begin{array}{l}\text { Most widely used } \\
\text { Validated for some kits }\end{array}$ \\
\hline Urine test & $93 \%$ & $92 \%$ & $\begin{array}{l}\text { Easy sampling method without } \\
\text { special skills and tools } \\
\text { Sampling cheaper than serum } \\
\text { sampling }\end{array}$ & $\begin{array}{l}\text { False negative results with } \\
\text { low concentrations of IgG }\end{array}$ & $\begin{array}{l}\text { Lower accuracy } \\
\text { Requires more time to interpret } \\
\text { Lack of availability }\end{array}$ \\
\hline
\end{tabular}

UBT, urea breath test; PPI, proton pump inhibitor; SAT, stool antigen test; ICA, immunochromatographic assay; IgG, immunoglobulin G. 
Surabaya on Java Island, three centers in Medan on Sumatera Island, and two centers in Makassar on Sulawesi Island. In addition, this test is not covered by Indonesian social insurance. With a cost of Indonesian Rupiah (IDR) 1,200,000 (U.S. Dollar [USD] 85 estimated in July 2019), this method is relatively expensive and may not become a common method for detection of $H$. pylori. Recently, ${ }^{13} \mathrm{C}$-UBT has been performed using a simpler infrared spectrophotometer, which is more compact, cost effective and easy procedure than the mass spectrometer. ${ }^{12}$ Most Indonesian gastroenterologists use this method to evaluate $H$. pylori positivity after eradication beside of SAT. ${ }^{19,20}$ According to the Asia-Pacific consensus to improve the accuracy of the test, the patients should stop taking bismuth salts and antibiotics for 4 weeks, PPI for 2 weeks and fast for at least 4 hours. ${ }^{18,21}$ These preparations are not convenient for most patients, especially those with severe symptoms. Because UBiT $^{\circledR}$-IR300 infrared spectrophotometers are not currently available, most Indonesian centers use a new type of infrared spectral analyzer (POCone FT-IR ${ }^{\circledR}$; Otsuka Pharmaceutical Co. Ltd., Tokyo, Japan), which is claimed to be simpler, easy to maintain, faster and accurate. We use a 75-mg tablet of ${ }^{13} \mathrm{C}$-urea, not a 100-mg tablet as previously described. ${ }^{22}$ In contrast to the recommendation for gurgling to avoid catalytic positive bacteria in the oral cavity and oropharynx, ${ }^{23}$ a film-coated tablet-based UBT (UBIT, Otsuka Pharmaceutical Co. Ltd.) is used without gargling.

Validation in the United States and Europe suggested a lower dose of ${ }^{13} \mathrm{C}$-UBT (75 to $125 \mathrm{mg}$ ) than the original recommendation (350 mg), but not lower than $75 \mathrm{mg}$ to avoid poor results. ${ }^{24}$ The reduction a dose of $50 \mathrm{mg}$ in children was found in several studies that have been used to diagnose $H$. pylori infection. ${ }^{22,25}$ At the same dose of ${ }^{13} \mathrm{C}$-urea, low production of endogenous $\mathrm{CO}_{2}$ in younger children has a relatively high isotope ratio of ${ }^{13} \mathrm{CO}_{2}$ to ${ }^{12} \mathrm{CO}_{2}{ }^{25}$ However, in Indonesia we use a similar dose for adults and children. Based on the manufacturer's instructions, we do not administer citric acid. A previous study suggested the use of citric acid to increase sensitivity and specificity, ${ }^{26}$ especially with long-term use of PPI. In addition, when citric acid pretreatment was not performed, the accuracy was decreased. ${ }^{27}$ We do not have data about modification of the lateral recumbent position for patients with partial gastrectomy. ${ }^{28}$ Collected breath samples were analyzed for ${ }^{13} \mathrm{C}$-UBT with a cutoff value of $2.5 \%$, as recommended by the manufacturer. Unfortunately, this cutoff has not been validated for adults and children and we are trying to validate it. The calculated optimal cutoff points of UBT are important in populations that have a low prevalence of $H$. pylori infection, because they (e.g., healthy volunteers) are able to express higher delta over baseline (DOB) values. In contrast, in patients with dyspepsia in whom the prevalence of infection is higher than in the normal population, low DOB values must be considered. ${ }^{29}$

The use of ${ }^{14} \mathrm{C}$ during pregnancy is not usually recommended because of radiation hazards. ${ }^{18}$ However, it has been reported that a lower dose of ${ }^{14} \mathrm{C}$-UBT can be used safely in children. ${ }^{25}$ In Indonesia, 16 centers provide ${ }^{14} \mathrm{C}$-UBT: nine centers in North Sumatera on Sumatera Island; one center in Jakarta, two centers in West Java, two centers in East Java and one center in Yogyakarta on Java Island; and one center on Bali Island. All the centers use the HUBT-20A1 analyzer (Headway, Shenzhen, China) with a ${ }^{14} \mathrm{C}$-urea capsule containing $27.8 \mathrm{kBq}$ of radiation. Following the manufacturer's instructions, we use a cutoff value of 50\% to detect $H$. pylori infection. Currently, we are validating ${ }^{14} \mathrm{C}$-UBT in difference rate of $H$. pylori infection. In areas such as Indonesia with a lack of access to endoscopy, the use of UBT could minimize the number of endoscopies and the associated expenses to the healthcare system and patients' discomfort. Modifications of the ${ }^{14} \mathrm{C}$-urea dose and breath-collection times may solve the problem of the use of ${ }^{14} \mathrm{C}$-UBT in pregnant women and children, although the use of ${ }^{14} \mathrm{C}$-UBT in these patients is still not accepted in Indonesia.

\section{STOOL ANTIGEN TEST}

The SAT is noninvasive and inexpensive, and its diagnostic accuracy is not dependent on age. ${ }^{30}$ Enzyme immunoassay (EIA) based on polyclonal antibodies was the first method of SAT and had high accuracy. ${ }^{31}$ However, most of the results were inconsistent, and a monoclonal antibody-based approach was developed, which has been shown to reduce false positive findings and increase specificity. ${ }^{32}$ The pretreatment monoclonal antigen technique was superior to polyclonal technique, with a specificity of $97 \%$ versus $94 \%$, sensitivity of $96 \%$ versus $90 \%$, positive predictive value of $96 \%$ versus $91 \%$ and negative predictive value of $97 \%$ versus $85 \% .^{33}$ Four to eight weeks of antisecretory therapy also showed that the monoclonal antigen was better than the polyclonal antigen. ${ }^{33,34}$ In Indonesia, the SAT does not require expensive special equipment and chemicals and is cheaper than UBT. It is widely used throughout the country with a cost of IDR 300,000 (USD 20 estimated July 2019). In addition, the SAT does not require fasting and, with novel monoclonal antibodies, does not require discontinuation of PPIs. ${ }^{35}$

EIA and immunochromatographic assay (ICA) are both methods of SAT. EIA has better accuracy than ICA, even though the latter uses monoclonal antibodies. ${ }^{36,37}$ EIA-based assays, such as the commercial kit Premier Platinum HpSA (Meridian Diagnostic, Cincinnati, OH, USA) may be applicable in Indonesia. After mixing the stool sample with $200 \mu \mathrm{L}$ of sample diluents, enzyme conjugate is added to the microplate. The mix was incubated for 1 hour at room temperature and washed five times. The results are read by spectrophotometry after one drop of stop solution is added to end the reaction. The manufacturer's recommendations indicate a positive result if absorbance $(450 / 630) \geq 0.160 .{ }^{38} \mathrm{~A}$ cutoff value of 0.300 is reported to provide the best diagnostic value, with sensitivity of 93.9\%, specificity of 95.7\% and accuracy of $94.8 \%$; a cutoff value of 0.130 provides less sensitivity 
(89.5\%) and specificity (83.3\%). ${ }^{39,40}$ However, most commercial laboratories in Indonesia are not interested in using this method because of higher costs and thus reduced potential profits.

ICA has the advantage of providing rapid diagnosis of $H$. pylori infection. ICA may be useful in developing countries with many remote areas, such as Indonesia. A proper accuracy of ICA-based SAT can be in stock in many hospitals in Indonesia, and the examination can be carried out in small laboratories, as this test does not require special equipment and experts. When it was applied in clinical practice for the first time, an acceptable sensitivity of $88 \%$ and a specificity of $94 \%$ were achieved. ${ }^{41}$ Most of our centers and commercial laboratories use a rapid SAT method with monoclonal antibodies based on recently developed lateral flow ICA, such as On-Site $H$. pylori Ag Rapid Test-cassette (CTK Biotech Inc., San Diego, CA, USA). ${ }^{18,32}$ This test is very suitable for daily practice because it has more practical steps. ${ }^{26}$ The manufacturer's instructions recommend applying 5 to $10 \mathrm{~mL}$ of faces to the device that contained with the antibody. If $H$. pylori antigen is present in the stool, a reaction between the antigen-antibodies and the dye will appear within 15 minutes as a red line in the instrument test zone. The negative result was determined if one red line appears in the control zone while the positive result was determined if two red lines appear in both control and test zone. The result is invalid if there is no red line in the control zone and the examination need to be repeated using a new tape. In addition, the $H$. pylori strain used in this test is different from that in Indonesia, ${ }^{42} \mathrm{sev}-$ eral factors affect the results of SAT. Low amounts of antigen due to low colonization in the stool and low ability to react can produce false negative results. ${ }^{20}$ In a country such as Indonesia, with a low prevalence of $H$. pylori, the density number of $H$. pylori is also low, suggesting a high risk of low sensitivity of the SAT. Incubation time also is an important factor. The sensitivity of readings at 30 and 60 minutes can reach 76.9\% and 78.6\%, respectively, compared with $59.1 \%$ at 20 minutes. ${ }^{25}$ Formless or watery stools can reduce the accuracy of the test due to dilution of antigens. ${ }^{37}$ If the sample is not tested within a short time (less than 7 days), it must be stored at low temperature $\left(-5^{\circ} \mathrm{C}\right.$ to $-25^{\circ} \mathrm{C}$ ). Testing of stool samples stored at $-80^{\circ} \mathrm{C}$ for 225 days still provided good sensitivity and specificity. ${ }^{37}$ In Indonesia, collecting stools is more difficult than collecting blood samples. People cannot predict their defecation time well, and many may not feel comfortable about the delivery process.

The accuracy of the SAT for H. pylori is a concern. A validation study of Pronto Dry (Medical Instruments Corporation, Solothurn, Switzerland) at Cipto Mangunkusumo Hospital in Jakarta reported sensitivity and specificity of only $66.7 \%$ and $78.9 \%$, respectively, with 0.274 as the cutoff value. ${ }^{43}$ In addition, of 54 of 63 dyspeptic patients (85.7\%) who tested positive based on several methods, 42 tested positive by the SAT only, which suggests a potential for false positive results. Therefore, the local validation test is very important, because differences in the antigenicity of $H$. pylori strains affect the result of the SAT. ${ }^{32}$

\section{SEROLOGY}

In general, detection of specific antibodies following exposure to various $H$. pylori antigens can be a useful method in clinical practice because it is acceptable to patients, cheap and fast. ${ }^{18}$ An important study reviewed 36 commercial kits used in 26,812 patients in different populations; the sensitivity ranged from $57 \%$ to $100 \%$ and the specificity from $31 \%$ to $100 \%{ }^{44}$ Thus, a validated serological test is useful for initial screening before the diagnosis is confirmed by histology or culture, especially in a country with a shortage of endoscopic centers. ${ }^{45}$ However, it must be noted that the test and treat strategy is not recommended in areas with a low prevalence of $H$. pylori. Our group showed that an enzyme-linked immunoassay (ELISA) kit (Eiken Co. Ltd., Tokyo, Japan) had low sensitivity when the cutoff value from the manufacturer's instructions (positive if $\geq 10$ $\mathrm{U} / \mathrm{mL}$, with sensitivity and specificity of $66.7 \%$ and $97.2 \%$, respectively) was used. We suggested using a cutoff value of $\geq 5.5 \mathrm{U} / \mathrm{mL}$, which increased the sensitivity to $86.7 \%$. ${ }^{13}$ The use of serological tests for screening patients with dyspepsia can save costs and reduce endoscopic workload by up to $30 \%$. $^{33}$ Nevertheless, serological tests are not recommended for children because of the problem of the level of $H$. pylori-specific antibodies. $^{30}$

Antibody preparations are closely related to the diagnostic accuracy of different kits. ${ }^{46}$ Kits made in Eastern countries will be more accurate in detecting $H$. pylori strains in Eastern countries than kits made in Western countries. The accuracy of diagnostic kits from Western countries was low when applied to Japanese patients. ${ }^{47,48}$ In a study that compared the diagnostic accuracy of ELISA kits from Western and Eastern countries for detection of immunoglobulin G (IgG) antibodies to H. pylori in Japan, the accuracy of the Western kit was 86.8\% and the accuracy of the Eastern kit was $92.3 \%{ }^{49}$ Therefore, the use of antigens of local $H$. pylori strains will affect the success of serological tests in Indonesia.

Serological tests use blood samples to detect IgG antibodies by ELISA. Similar to the SAT, the accuracy of EIA-based serological tests is better than that of ICA-based tests. A study that compared 29 commercial serological tests showed that nine of 17 EIA-based tests but only one in 12 ICA-based tests had an accuracy of more than 90\%. ${ }^{2}$ Immunoblot assay has higher specificity but lower sensitivity than EIA. This method requires special expertise and has high costs, so it is not used in clinical laboratories in Indonesia. ${ }^{17}$ ELISA is the most commonly used method in Indonesia. After $H$. pylori has been successfully treated, IgG antibodies to $H$. pylori will last for several months. ${ }^{50}$ In addition, serological tests can result in false negatives, which may occur with new infections when antibody levels are not sufficiently elevated, because IgG antibodies appear approxi- 
mately 21 days after $H$. pylori infection. ${ }^{51}$ We are currently validating an ICA-based kit (MP Diagnostics ASSURE ${ }^{\circledR}$; MP Biomedicals, Santa Ana, CA, USA) against histopathology as the gold standard. They proposed a recombinant current infection marker as an indication of current infection for covering the lack of serology.

\section{URINE TEST}

Several tests for detection of antibodies to $H$. pylori using urine and saliva samples have shown high sensitivity and specificity. ${ }^{52-54}$ Sampling of urine and saliva can be performed easily without the need for special skills or tools and is cheaper than sampling of serum. However, a major problem is that the concentrations of $H$. pylori antibodies in saliva and urine are lower than in serum. ${ }^{17}$ False negative results can occur with urinebased ELISA. H. pylori-specific IgG has low concentration in the urine. A study showed that a commercial kit (RAPIRUN ${ }^{\circledR}$ stick, Otsuka Pharmaceutical Co., Ltd.) to detect H. pylori antibodies in urine was reliable for detecting $H$. pylori infection in Indonesia. ${ }^{55}$ In this test, $0.3 \mathrm{~mL}$ of fresh urine is mixed with $0.3 \mathrm{~mL}$ of dilute solution to make an approximately 2-fold dilution, and a test stick is placed in the mixture. A colloidal gold-conjugated antihuman IgG $(\mathrm{Fc})$ polyclonal antibody (goat) is enclosed inside the test stick. $H$. pylori antigen is used to immobilize the test line of the evaluation section, and the anti-human IgG polyclonal antibody is used as the control line. ${ }^{56}$ If two red bands appear on the test line after the sample is applied for 15 minutes at $25^{\circ} \mathrm{C}$ to $30^{\circ} \mathrm{C}$, the result is considered positive. The result is considered negative if a red band appears on the control line only. The result is considered invalid due to error in the assay steps or excessively diluted urine if the red band is absent in the control line. The RAPIRUN ${ }^{\circledast}$ test validation result in Indonesia found sensitivity, specificity, positive predictive value, negative predictive, and accuracy of 83.3\%, 94.7\%, 71.4\%, 97.3\%, and 93.2\%, respectively. In Japan and Vietnam, rapid urine tests had a sensitivity of 93.1\%, a specificity $92.3 \%$ and an accuracy of 92.0\%. Our group also used RAPIRUN ${ }^{\circledR}$ among minor ethnic groups in remote areas of North Sulawesi and found identical results to serological test findings. ${ }^{57}$ When the urine test showed a positive result, we used a disposable gastric brush to obtain gastric juice and a small amount of gastric tissue for $H$. pylori culture. However, in our experience, RAPIRUN ${ }^{\circledR}$ had less accuracy in areas with low prevalence of $H$. pylori in Indonesia ${ }^{58}$ and required more time to interpret rather than manual instruction.

\section{CONCLUSIONS}

The use of noninvasive $H$. pylori testing in Indonesia may reduce the overall endoscopic workload and the financial burden on Indonesian social insurance. Validated UBT and SAT are considered practical approaches for the detection of $H$. pylori infection in Indonesia, with serological and urine tests as alternative strategies.

\section{CONFLICTS OF INTEREST}

No potential conflict of interest relevant to this article was reported.

\section{ORCID}

Muhammad Miftahussurur https://orcid.org/0000-0003-1415-6033

\section{REFERENCES}

1. Correa P. Human gastric carcinogenesis: a multistep and multifactorial process. First American Cancer Society Award Lecture on Cancer Epidemiology and Prevention. Cancer Res 1992;52:67356740.

2. Burucoa C, Delchier JC, Courillon-Mallet A, et al. Comparative evaluation of 29 commercial Helicobacter pylori serological kits. Helicobacter 2013;18:169-179.

3. Syam AF, Miftahussurur M, Makmun D, et al. Risk factors and prevalence of Helicobacter pylori in five largest islands of Indonesia: a preliminary study. PLoS One 2015;10:e0140186.

4. Sahara S, Sugimoto M, Vilaichone RK, et al. Role of Helicobacter pylori cagA EPIYA motif and vacA genotypes for the development of gastrointestinal diseases in Southeast Asian countries: a metaanalysis. BMC Infect Dis 2012;12:223.

5. Destura RV, Labio ED, Barrett LJ, et al. Laboratory diagnosis and susceptibility profile of Helicobacter pylori infection in the Philippines. Ann Clin Microbiol Antimicrob 2004;3:25.

6. Thevakumar K, Chandren JR, Perez-Perez GI, et al. Assessment of risk and sero-prevalence of Helicobacter pylori colonization among remote orang Asli tribes in peninsula Malaysia. PLoS One 2016;11:e0159830.

7. Miftahussurur M, Syam AF, Makmun D, et al. Helicobacter pylori virulence genes in the five largest islands of Indonesia. Gut Pathog 2015;7:26.

8. Waskito LA, Miftahussurur M, Lusida MI, et al. Distribution and clinical associations of integrating conjugative elements and cag pathogenicity islands of Helicobacter pylori in Indonesia. Sci Rep 2018;8:6073.

9. Miftahussurur M, Syam AF, Nusi IA, et al. Surveillance of Helicobacter pylori antibiotic susceptibility in Indonesia: different resistance types among regions and with novel genetic mutations. PLoS One 2016;11:e0166199.

10. Miftahussurur M, Waskito LA, Syam AF, et al. Alternative eradication regimens for Helicobacter pylori infection in Indonesian regions with high metronidazole and levofloxacin resistance. Infect Drug Resist 2019;12:345-358.

11. Makmun D. Present status of endoscopy, therapeutic endoscopy and the endoscopy training system in Indonesia. Dig Endosc 
2014;26 Suppl 2:2-9.

12. Miftahussurur M, Doohan D, Nusi IA, et al. Gastroesophageal reflux disease in an area with low Helicobacter pylori infection prevalence. PLoS One 2018;13:e0205644.

13. Miftahussurur M, Nusi IA, Akil F, et al. Gastric mucosal status in populations with a low prevalence of Helicobacter pylori in Indonesia. PLoS One 2017;12:e0176203.

14. Miftahussurur M, Yamaoka Y. Diagnostic methods of Helicobacter pylori infection for epidemiological studies: critical importance of indirect test validation. Biomed Res Int 2016;2016:4819423.

15. Graham DY, Miftahussurur M. Helicobacter pylori urease for diagnosis of Helicobacter pylori infection: a mini review. J Adv Res 2018;13:51-57.

16. Klein PD, Malaty HM, Martin RF, Graham KS, Genta RM, Graham DY. Noninvasive detection of Helicobacter pylori infection in clinical practice: the $13 \mathrm{C}$ urea breath test. Am J Gastroenterol 1996;91:690-694.

17. Patel SK, Pratap CB, Jain AK, Gulati AK, Nath G. Diagnosis of Helicobacter pylori: what should be the gold standard? World J Gastroenterol 2014;20:12847-12859.

18. Talebi Bezmin Abadi A. Diagnosis of Helicobacter pylori using invasive and noninvasive approaches. J Pathog 2018;2018:9064952.

19. Syam AF. Current situation of Helicobacter pylori infection in Indonesia. M J Indones 2017;25:263-266.

20. Dore MP, Pes GM, Bassotti G, Usai-Satta P. Dyspepsia: when and how to test for Helicobacter pylori infection. Gastroenterol Res Pract 2016;2016:8463614.

21. Sheu BS, Wu MS, Chiu CT, et al. Consensus on the clinical management, screening-to-treat, and surveillance of Helicobacter pylori infection to improve gastric cancer control on a nationwide scale. Helicobacter 2017;22:e12368.

22. Gatta L, Ricci C, Tampieri A, et al. Accuracy of breath tests using low doses of 13C-urea to diagnose Helicobacter pylori infection: a randomised controlled trial. Gut 2006;55:457-462.

23. Sano N, Ohara S, Koike T, et al. Influence of urease activity of the oral cavity and oropharynx on 13C-urea breath test. Nihon Shokakibyo Gakkai Zasshi 2004;101:1302-1308.

24. Calvet X, Lehours P, Lario S, Mégraud F. Diagnosis of Helicobacter pylori infection. Helicobacter 2010;15 Suppl 1:7-13.

25. El-Shabrawi M, El-Aziz NA, El-Adly TZ, et al. Stool antigen detection versus (13)C-urea breath test for non-invasive diagnosis of pediatric Helicobacter pylori infection in a limited resource setting. Arch Med Sci 2018;14:69-73.

26. Vaira D, Gatta L, Ricci C, Di Mario F, Lanzini A. Accuracy of urea breath tests tablets after 10 minutes compared with standard 30 minutes to diagnose and monitoring Helicobacter pylori infection: a randomized controlled trial. J Clin Gastroenterol 2009;43:693694.

27. Calvet X, Sánchez-Delgado J, Montserrat A, et al. Accuracy of diagnostic tests for Helicobacter pylori: a reappraisal. Clin Infect Dis 2009;48:1385-1391.

28. Yin SM, Zhang F, Shi DM, et al. Effect of posture on (13)C-urea breath test in partial gastrectomy patients. World J Gastroenterol 2015;21:12888-12895.

29. Parente F, Bianchi Porro G. The (13)C-urea breath test for non-invasive diagnosis of Helicobacter pylori infection: which procedure and which measuring equipment? Eur J Gastroenterol Hepatol 2001;13:803-806.

30. Rana R, Wang SL, Li J, Wang YX, Rao QW, Yang CQ. Helicobacter pylori infection: a recent approach to diagnosis and management J Biomed 2017;2:45-56.

31. Makristathis A, Pasching E, Schütze K, Wimmer M, Rotter ML, Hirschl AM. Detection of Helicobacter pylori in stool specimens by PCR and antigen enzyme immunoassay. J Clin Microbiol 1998;36:2772-2774.

32. Shimoyama T. Stool antigen tests for the management of Helicobacter pylori infection. World J Gastroenterol 2013;19:8188-8191.

33. Gisbert JP, Calvet X. Helicobacter pylori “test-and-treat" strategy for management of dyspepsia: a comprehensive review. Clin Transl Gastroenterol 2013;4:e32.

34. Gisbert JP, Pajares JM. Stool antigen test for the diagnosis of Helicobacter pylori infection: a systematic review. Helicobacter 2004;9:347-368.

35. Kodama M, Murakami K, Okimoto T, et al. Influence of proton pump inhibitor treatment on Helicobacter pylori stool antigen test. World J Gastroenterol 2012;18:44-48.

36. Krogfelt KA, Lehours P, Mégraud F. Diagnosis of Helicobacter pylori Infection. Helicobacter 2005;10 Suppl 1:5-13.

37. Shimoyama T, Sawaya M, Ishiguro A, Hanabata N, Yoshimura T, Fukuda S. Applicability of a rapid stool antigen test, using monoclonal antibody to catalase, for the management of Helicobacter pylori infection. J Gastroenterol 2011;46:487-491.

38. Veijola L, Myllyluoma E, Korpela R, Rautelin H. Stool antigen tests in the diagnosis of Helicobacter pylori infection before and after eradication therapy. World J Gastroenterol 2005;11:7340-7344.

39. Konstantopoulos N, Rüssmann H, Tasch C, et al. Evaluation of the Helicobacter pylori stool antigen test (HpSA) for detection of Helicobacter pylori infection in children. Am J Gastroenterol 2001;96:677-683.

40. Forné M, Domínguez J, Fernández-Bañares F, et al. Accuracy of an enzyme immunoassay for the detection of Helicobacter pylori in stool specimens in the diagnosis of infection and posttreatment check-up. Am J Gastroenterol 2000;95:2200-2205.

41. Vaira D, Malfertheiner P, Mégraud F, et al. Diagnosis of Helicobacter pylori infection with a new non-invasive antigen-based assay. HpSA European study group. Lancet 1999;354:30-33.

42. Avisiena A, Nusi IA, Maimunah U, et al. Diagnostic values of Helicobacter pylori stool antigen immunochromatitographic method compared to histopathology in dyspepsia patient. The New Armenian Med J 2019;13:13-19.

43. Syam AF, Rani AA, Abdullah M, et al. Accuracy of Helicobacter pylori stool antigen for the detection of Helicobacter pylori infection in dyspeptic patients. World J Gastroenterol 2005;11:386388. 
44. Laheij RJ, Straatman H, Jansen JB, Verbeek AL. Evaluation of commercially available Helicobacter pylori serology kits: a review. J Clin Microbiol 1998;36:2803-2809.

45. Lopes AI, Vale FF, Oleastro M. Helicobacter pylori infection: recent developments in diagnosis. World J Gastroenterol 2014;20:9299-9313.

46. Wang YK, Kuo FC, Liu CJ, et al. Diagnosis of Helicobacter pylori infection: current options and developments. World J Gastroenterol 2015;21:11221-11235.

47. Leung WK, Ng EK, Chan FK, Chung SC, Sung JJ. Evaluation of three commercial enzyme-linked immunosorbent assay kits for diagnosis of Helicobacter pylori in Chinese patients. Diagn Microbiol Infect Dis 1999;34:13-17.

48. Miwa H, Kikuchi S, Ohtaka K, et al. Insufficient diagnostic accuracy of imported serological kits for Helicobacter pylori infection in Japanese population. Diagn Microbiol Infect Dis 2000;36:9599.

49. Obata Y, Kikuchi S, Miwa H, Yagyu K, Lin Y, Ogihara A. Diagnostic accuracy of serological kits for Helicobacter pylori infection with the same assay system but different antigens in a Japanese patient population. J Med Microbiol 2003;52(Pt 10):889-892.

50. Kosunen TU, Seppälä K, Sarna S, Sipponen P. Diagnostic value of decreasing IgG, IgA, and IgM antibody titres after eradication of Helicobacter pylori. Lancet 1992;339:893-895.

51. Mégraud F, Lehours P. Helicobacter pylori detection and antimicrobial susceptibility testing. Clin Microbiol Rev 2007;20:280-322.

52. Katsuragi K, Noda A, Tachikawa T, et al. Highly sensitive urine- based enzyme-linked immunosorbent assay for detection of antibody to Helicobacter pylori. Helicobacter 1998;3:289-295.

53. Miwa H, Hirose M, Kikuchi S, et al. How useful is the detection kit for antibody to Helicobacter pylori in urine (URINELISA) in clinical practice? Am J Gastroenterol 1999;94:3460-3463.

54. Kato M, Asaka M, Saito M, et al. Clinical usefulness of urine-based enzyme-linked immunosorbent assay for detection of antibody to Helicobacter pylori: a collaborative study in nine medical institutions in Japan. Helicobacter 2000;5:109-119.

55. Syam AF, Miftahussurur M, Uwan WB, Simanjuntak D, Uchida T, Yamaoka Y. Validation of urine test for detection of Helicobacter pylori infection in I ndonesian population. Biomed Res Int 2015;2015:152823.

56. Quach DT, Hiyama T, Shimamoto F, et al. Value of a new sticktype rapid urine test for the diagnosis of Helicobacter pylori infection in the Vietnamese population. World J Gastroenterol 2014;20:5087-5091.

57. Miftahussurur M, Tuda J, Suzuki R, et al. Extremely low Helicobacter pylori prevalence in North Sulawesi, Indonesia and identification of a Maori-tribe type strain: a cross sectional study. Gut Pathog 2014;6:42.

58. Miftahussurur M, Shiota S, Suzuki R, et al. Identification of Helicobacter pylori infection in symptomatic patients in Surabaya, Indonesia, using five diagnostic tests. Epidemiol Infect 2015;143:986-996. 